\title{
GOOD SCIENTIFIC PRACTICE AND ACADEMIC REVIEWS
}

Accepted: 20 September 2021; published online: 11 November 2021

\begin{abstract}
Academic reviews (hereinafter "reviews") are an integral part of legal journals. While their purpose and usefulness are at times disputed, all sub-disciplines of legal studies nevertheless argue in equal measure that a lack of substantial academic exchange by way of reviews would result in the impoverishment of scientific discourse. In German criminal law scholarship, two recent cases have sparked debate about whether certain rules should govern the publication of such reviews. The following remarks are intended to provide a thought-provoking impulse on the matter.
\end{abstract}

\section{INTRODUCTION}

Opinions on the topic of reviews can take one of two alternative perspectives. The broad perspective, which is directed at the publication system as a whole, leads to the conclusion that there are currently not enough reviews of high-quality substance. This weakens scientific discourse as the reviews that are published are too few in number and too uncritical in nature. ${ }^{1}$ The review system has "tended to develop into a book advertising system: Reviews are dominated by content references to the detriment of critical assessment."2 The

* The author is a director at the Max Planck Institute for the Study of Crime, Security and Law in Freiburg and an honorary professor at the Law Faculty of the Humboldt-Universität zu Berlin. She would like to thank her colleagues for their constructive exchanges on the subject matter at hand, especially Elisa Hoven and Thomas Weigend, who organized a debate on the topic. A German version of this paper first appeared in the Neue Juristische Wochenschrift (NJW 2021, 1933). Translation by Christopher Murphy. Contact e-mail: t.hoernle@csl.mpg.de.

${ }^{1}$ Schulze-Fielitz in Burgi, Zur Lage der Verwaltungsrechtswissenschaft (Die Verwaltung, Beiheft 12), 2017, 179 (185 ff.); Zimmermann NJW 2016, 3142 (3143) on the private law situation.

${ }^{2}$ Wissenschaftsrat, Perspektiven der Rechtswissenschaft in Deutschland. Situation, Analysen, Empfehlungen, 2012, 50 f. (Author translation of the original German quote). 
second, narrower, perspective takes a different angle: It asks whether limits need to be observed when writing and publishing reviews in order to steer an otherwise abundant "will to criticize" along more objective and factual lines. The two perspectives are not mutually exclusive: The requirement to engage seriously, intensively, and critically with the text under review is not counteracted by the requirement to do so objectively.

The following reflections are (also) prompted by two recent reviews that were published in the German online journal Zeitschrift für Internationale Strafrechtsdogmatik (ZIS). These reviews stirred up considerable commotion among criminal law scholars and further afield. In one of these reviews, the reviewer, who holds a university chair in Bonn, undertook a detailed and highly critical assessment of the habilitation thesis written by a colleague in Cologne. ${ }^{3}$ The other involved a scathing review of a doctoral thesis by the holder of a senior professorship in Mannheim. ${ }^{4}$ The subject of this article does not deal with the content of the abovementioned book reviews per se (for example, in the form of a reply or even a "review duel" ); the aim is rather to continue a debate that Helmuth Schulze-Fielitz initiated a few years back concerning requirements and standards for reviewers in general. ${ }^{6}$ I will sketch some ideas for possible rules and a subsequent recommendation. However, before so doing it is necessary to address the objection that rules are not necessary in the first place and that discussions are not only superfluous but even harmful.

\section{RULES FOR REVIEWS - SUPERFLUOUS OR HARMFUL?}

After the dust that was thrown up by the aforementioned reviews settled, opinion was expressed that rules or limits on what should or should not be included in a review are not necessary. Following this

\footnotetext{
${ }^{3}$ Stuckenberg ZIS 2021, 279.

${ }^{4}$ Kuhlen ZIS 2020, 327. The author of the reviewed dissertation has worked in the Criminal Law Department of the Max Planck Institute as PostDoc under the supervision of this author (Tatjana Hörnle) and is now continuing her career within the federal government. Because Kuhlen combined his review with reflections on the gloomy outlook of German criminal law studies (op. cit., 323), the editors of the ZIS organized a special issue (H. 10/2020; authors: Ambos, Greco, Hörnle, Rotsch, Schünemann). This special issue demonstrated, above all, how varied the associations are that Kuhlen's sweeping and bleak prognosis triggered.

${ }^{5}$ Schulze-Fielitz in Burgi, Zur Lage der Verwaltungsrechtswissenschaft, 179 (202).

${ }^{6}$ Schulze-Fielitz in Burgi, Zur Lage der Verwaltungsrechtswissenschaft, 179.
} 
opinion, decisions on content and style should be left solely to the person writing the review. This approach draws support from the widely upheld understanding of freedom of expression and scientific independence as constitutional rights. These constitutional rights only reach their limits when the nature of the criticism in question takes on an insulting or defamatory character. ${ }^{7}$ This interpretation is correct in as far as legal limits are concerned, especially when it comes to using the criminal law to enforce them. Indeed, the use of criminal libel suits in the scientific community is to be discouraged. ${ }^{8}$ Yet this is not the end of the matter. Even though constitutional and criminal law grant considerable room for freedom of expression and protect authors against interventions by state officials and courts, from the perspective of scientific ethics it may nevertheless be advisable to have rules that reviewers and journal editors should follow because they correspond with shared ideas of good scientific practice. Another, separate, point is the extent to which large scientific organizations (such as the German Research Foundation) should enforce standards (this would require a formalization of norms and procedures). The present discussion is only concerned with the content of some basic rules for good scientific practice when writing reviews in our field.

The strongest counterargument is that discussing rules for reviews could result in harmful consequences. Among some of those who prefer to avoid discussions on the matter, one source of unease seems to be the fear that rules involve the kind of restrictions on freedom of expression that are outlined by the keyword cancel culture. ${ }^{9}$ Such concerns are unfounded. A serious understanding of scientific ethics differs from the self-righteous and unreflected moralizing ${ }^{10}$ that typically fuels cancel culture debates. Insisting on objective criticism is intended to counteract precisely the emotionalizations found in fragmented societies that quickly turn into demands for mutual marginalization and exclusion. Others warn that the desire to en-

\footnotetext{
${ }^{7}$ On the high hurdle set by the $B V \operatorname{erf} G$ concerning classification as defamatory criticism, see BVerfG NJW 2019, 2600; NJW 2016, 2870.

${ }^{8}$ For more on one such instance of litigation (Calvo-Goller v. Weiler), which the author of the book on international criminal law lost, see Horstkotte LTO 5.3.2011 (https://www.lto.de/recht/hintergruende/h/der-fall-weiler-vs-calvo-goller-mehr-alseine-frage-der-ehre-oder-schande/, last accessed 27.4.2021); Weiler European Journal of International Law (EJIL) 2010, 967.

${ }^{9}$ For example, see Dershowitz, Cancel Culture: The Latest Attack on Free Speech and Due Process, 2020.

${ }^{10}$ For criticism of this phenomenon, see Tosi/Warmke, Grandstanding: The Use and Abuse of Moral Talk, 2020.
} 
hance scientific quality can result in unpleasant consequences, as any type of "quality assurance" almost implicitly entails bureaucratic procedures. ${ }^{11}$ A discussion on standards of scientific ethics does not, however, insist on the creation of formal structures to verify compliance. The far more modest request made here argues in favor of a handful of well-reasoned and voluntary commitments.

The question naturally arises whether it is even necessary to discuss basic rules of good scientific practice with regard to reviews. Are we simply wasting precious time on a superfluous debate? It would indeed be superfluous if journal editors tactfully but consistently reject reviews when deemed necessary or at least ask for their reformulation. It is certainly true that this does, on the whole, seem to be the case. Nevertheless, from time to time, and especially after a failure of control mechanisms, it makes sense to publicly reflect on the minimum standards that a review should observe. A further argument raised to support the notion that it is not necessary to formulate a core set of rules for good scientific practice refers to self-regulation within the scientific community. This line of argument posits that those who are subjected to unfair criticism can defend themselves by journalistic means; furthermore, it is suggested that unobjective reviews place the reviewer, in particular, in a bad light. What is certainly true is that authors have to accept objectively formulated and reasoned reviews. ${ }^{12}$ Yet this approach does not stipulate where the boundary between factual criticism and personal attack lies, nor how this boundary, which the $B V \operatorname{erf} G$ applies very strictly in its decisions, ${ }^{13}$ should be adjusted from the perspective of scientific ethics. Such considerations cannot be sidestepped by pointing out that rude comments have always existed and that authors should not react "squeamishly". While there is probably agreement that the yardstick should not be set by heightened forms of personal sensitivity, ${ }^{14}$ it is also necessary to avoid the opposite extreme, which lies in underes-

${ }^{11}$ See Kuhlen ZIS 2020, 327 (335). Anyone with experience of universities and other academic institutions will agree with this observation.

${ }^{12}$ On the obligation of authors to accept reasoned criticism in the discussed books, see Schulze-Fielitz in Burgi, Zur Lage der Verwaltungsrechtswissenschaft, 179 (202 f.).

13 BVerfG NJW 2019, 2600; NJW 2016, 2870.

${ }^{14}$ For a discussion on so-called "trigger warnings" from a U.S. university perspective, see Laguardia et al. Journal of Legal Education 66 (2017) 882. Nevertheless, it should be pointed out that even a benevolent view of the gentle treatment of young adults cannot be transferred to the review of academic literature. 
timating the consequences of unobjective criticism for authors, for readers, and for the broader scientific system.

First, once the initial sparks have begun to fly, it is not possible to simply rebut a problematic review and stop a scandal from developing (to put the genie back in the bottle, so to speak). A realistic assessment of the situation must assume that even the readers of academic journals will not always correspond to the ideal concept of a scientific community in which rational beings will always be convinced exclusively by the better argument. Emotions should not be underestimated. The enjoyment provided by gossiping is widespread; so, too, is the somewhat less common - but certainly not infrequent indulgence in the strong emotion of schadenfreude. A text that pounds out its opinion in a crude manner has far greater entertainment value than a factual point-by-point reply designed to clarify the situation. Such a reply will inevitably be more boring and, for this reason alone, will find far fewer readers than the original critical review - if it is published at all. Moreover, the difference between print media and free online journals should not be understated. By sending links, texts with "scandal potential" are accessible to a much larger group of people than is the case with print media. Many recipients will be able to judge content details only to a limited extent or not at all (even if they have studied the same subject) and they most likely will not take note of a factual reply at a later date. The public image is thus inevitably shaped asymmetrically, not only shortly after the publication of the review but also for a long time to come. After all, the right to be forgotten is notoriously difficult to enforce if content is available in the internet. ${ }^{15}$ Under such conditions, greater attention is needed than in the past as to whether reviewers observe minimum standards of neutrality and objectivity.

Second, lapses in reviews can have an effect far beyond the sphere of the book's author. In discussions on the matter, a clear difference emerges between the assessment of such incidents among older, established colleagues and among younger, up-and-coming researchers. For those who do not yet hold professorships, scandalous reviews are threatening. They reinforce the general impression that a career in academia is beset with many unknowns. In the field of law, where exceptional graduates are courted and have access to either well-paid or at any rate secure positions as judges and in the civil

\footnotetext{
${ }^{15}$ Gstrein, Das Recht auf Vergessenwerden als Menschenrecht, 2016; Weismantel, Das „Recht auf Vergessenwerden“ im Internet nach dem „Google-Urteil“ des EuGH, 2017; Behrendt DVBl 2020, 1448.
} 
service, this uncertainty is not a good starting point for the promotion of academic careers. ${ }^{16}$

Third, unobjective and impertinent reviews damage the very system on which they are founded. The idea behind reviews is to give many colleagues the opportunity to inform themselves about new literature in a time-saving and reliable fashion, in a manner that goes beyond the standard book blurb or publisher's advertising text. In writing a review, it is important to take an analytically-distanced approach to the work's contents and arguments in order to appropriately reflect on them, detect any weaknesses, where applicable, and elaborate on their relevance within the scientific field and its trends. ${ }^{17}$ Thorough or even reliable reviewing is no longer possible when (conscious or unconscious) emotions cloud the view of the reviewer and make impartiality and the "necessary distance" impossible. From the reader's point of view, a review is useless as soon as doubts arise about the personal and emotional neutrality of its author. Journals neglect their academic service function if they expect their readership to assess the individual motivations of a reviewer. Above all else, the overall quality of academic exchange is greatly threatened if the guiding principle of objectivity is allowed to slowly disintegrate. $^{18}$

\section{BASIC RULES FOR REVIEWS}

\subsection{Lack of Neutrality as a Ground for Exclusion}

Under certain unusual circumstances, reviewers should refrain from writing reviews in the first place; if they nevertheless do so, then editorial boards should not accept them for publication. SchulzeFielitz assumes a broad range of incompatibilities, with suggestions that are intended to rule out even the abstract danger of a lack of neutrality; these are similar to the German Research Foundation's rules on questions of bias. ${ }^{19}$ Accordingly, prospective reviewers should refrain from discussing, among others, the following works: publications by faculty colleagues; postdoctoral theses (Habilita-

\footnotetext{
${ }^{16}$ For more on this, see Hörnle ZIS 2020, 468 (470).

${ }^{17}$ On the importance of reviews, see Schulze-Fielitz in Burgi, Zur Lage der Verwaltungsrechtswissenschaft, 179 (180 ff.).

${ }^{18}$ See also Hilgendorf in Gadenne/Neck, Hans Albert und der Kritische Rationalismus, 2021, 279 (290 f.).

19 Located at: https://www.dfg.de/formulare/10_201/.
} 
tionsschriften) by competing career applicants; treatises and commentaries if the potential reviewer has a similar treatise or commentary on the market. ${ }^{20}$ Whether one should draw the circle of rules that must be observed so broadly is open to debate. The criteria of "competing applicants" or "author of a similar publication" could greatly reduce the number of possible reviewers for a book.

Absolute limits would have to be drawn for two specific circumstances. First, one should refrain from reviewing when the reviewer's own professional reputation is linked to that of the author. This is typical in cases concerning the work of the reviewer's own doctoral and post-doctoral students. In the case of second opinions for academic qualification theses, the situation depends on whether the reviewer in question supervised the development and writing of the work. If this is the case, the neutral and distanced perspective that is necessary for a review is hardly possible.

Another question is whether writing a second opinion for the purpose of faculty proceedings is generally - irrespective of the reviewer's supervisory role - an indication for a lack of neutrality if the same person chooses to follow up with a review for an academic journal. This is a subject of contentious debate. ${ }^{21}$ We must assume that the impressions gained by writing a second opinion about a thesis will also shape the content of the subsequent book review. However, this psychological bias can only be classified as potentially harmful for a book review if the implicit assumption is that such opinions often are not based on neutral assessments but the product of collegial consideration or other non-scholarly motives.

Second, reviews are not appropriate if previous interactions between the author and the reviewer display peculiarities that would impede the latter's neutrality. Close personal relationships ought to be mentioned here, ${ }^{22}$ as should conflicts resulting from previous professional or social constellations. ${ }^{23}$ The same rule should also

\footnotetext{
${ }^{20}$ Schulze-Fielitz in Burgi, Zur Lage der Verwaltungsrechtswissenschaft, 179 (197 f.).

${ }^{21}$ If one subscribes to the view that having written a second opinion commissioned by a faculty stands in the way of writing a book review, the author of the current article should not have discussed the thesis of Boris Burghardt in RphZ 2019, 333 , because it was a second opinion that introduced her to this excellent work.

${ }^{22}$ See also No. 1 of the German Research Foundation's rules (above, Fn. 19) on bias (first-degree consanguinity, marriage, civil partnership, de facto relationship) as well as $\mathrm{Nr} .8$ (other relationships and personal ties).

${ }^{23}$ Nr. 8 of the German Research Foundation's rules on bias (above, Fn. 19).
} 
apply to academic qualification theses if the potential reviewer stands in conflict with the supervisor of the thesis. ${ }^{24}$ In the case of the aforementioned review by the colleague in Bonn, a conflict had been brewing in the background due to two appointment procedures that both involved unusual interventions.

\subsection{Reading the Reviewed Work Is Mandatory}

The rule that one should only write a review if one has read the material to be reviewed ${ }^{25}$ may seem almost too trite to be worth mentioning. Yet, even this seemingly self-evident detail is not always heeded: In December 2020, a statement appeared on the preceding debate about the scathing review from a professor in Mannheim, mentioned above. In this statement, the author supported certain conclusions about the book under review while at the same time confessing to have not actually read it. ${ }^{26}$ It should be equally obvious that editors must read submitted manuscripts. However, here too, it cannot be completely ruled out that occasionally editors base their decision on the fact that the author is a well-known professor.

\subsection{No Personal Attacks}

Criticism, especially the cutting kind, should refer exclusively to the content of the work under discussion. General statements describing the personality of authors and attributing to them certain dispositions and abilities (or lack thereof) should be avoided. It is one thing, for example, to describe a train of thought as illogical; it is another to infer a general inability to think logically. In general, it is a difficult task to infer dispositions and personal abilities from observing what others do, say, and write. For this reason alone, error-prone generalizations should be avoided. They are also superfluous, because seriously fact-oriented readers are interested in the content of the book and not in attempts to capture the personality of its author (this may admittedly play a role in the "scandalous review" category, but friends of this genre tend to be unconcerned about how well-founded the reviewer's conclusions are). When statements about book authors are sweeping and extremely negative, even those readers who are not

\footnotetext{
${ }^{24}$ On the prevalence of "proxy wars", see Schulze-Fielitz in Burgi, Zur Lage der Verwaltungsrechtswissenschaft, 179 (201).

${ }^{25}$ Schulze-Fielitz in Burgi, Zur Lage der Verwaltungsrechtswissenschaft, 179 (199 f.).

${ }^{26}$ Mitsch ZIS 2020, 522.
} 
aware of a conflict in the background will begin to doubt the quality and veracity of the review and will not classify it as a reliable assessment. The consequences that personal attacks can have on the authors, as well as on up-and-coming researchers in general, have already been highlighted above.

\subsection{Focus on the Book That Is Being Discussed}

The review of a single book is not the place to vent frustrations about general social or science policy developments. ${ }^{27}$ Anyone who suspects that science policy decisions promoting excellence and women ${ }^{28}$ or generous funding for stays abroad ${ }^{29}$ could produce problematic side effects in publications should look into this head on, instead of confining themselves to murmuring in the dark. Of course, it is a tedious process to test hypotheses in multifactorial contexts, not only because science policy (and its consequences) ${ }^{30}$ would have to be recorded and distinguished from other factors. Obviously, this cannot be done with the methods available to legal studies, and a social science study cannot be replaced by a few sentences in the brief format of a book review. Moreover, the inclusion of a few sentences in a review about the deplorable condition of one's academic field is not only an unsuitable way to increase knowledge, but it is especially unfair to those whose book is being reviewed. A neutral stance is quickly lost when reviewers are motivated by pre-formed theses and decide to review the book on the desk not as a work in itself but as an indication of phenomena they have already previously classified as troubling. This approach promotes a selective and distorted perception of the book's content.

\section{REDUCE POLEMIC TO IMPROVE REVIEW QUALITY}

While disregard of the aforementioned rules should prompt editors and editorial boards to reject a review, one can also address authors with softer recommendations regarding style. What about polemic

\footnotetext{
${ }^{27}$ For more on this, see Hörnle ZIS 2020, 468 (469).

${ }^{28}$ Kuhlen ZIS 2020, 327 (335).

${ }^{29}$ Stuckenberg ZIS 2021, 279 (292 Fn. 87) complained about the violation of a non-cumulation rule.

${ }^{30}$ On science policy and the mechanisms for the attribution of reputation, see Weingart in Hilgendorf/Schulze-Fielitz, Selbstreflexion der Rechtswissenschaft, 2015, 151.
} 
that, while not directed against an author but rather against the content of their work, is formally and stylistically such that it will annoy some readers? Schulze-Fielitz rightly points out that journals should accept the decision to hone arguments polemically. ${ }^{31}$ Even if one is critical of the use of polemic as a mode of communication (for which there are good reasons), it would be virtually impossible to draw a sufficiently clear line, since questions of personal style and taste would play a role in any such demarcation. At most, editors may inquire whether reviewers are aware of the drastic nature of their comments and whether this style is intentional.

Importantly, this approach is not tantamount to recommending reviewers to combine any number of piercing and exaggerated formulations according to their own personal temperament and mood. When used sparingly and when properly formulated, polemic can highlight criticism and help anchor it in the memory of readers. ${ }^{32}$ What is crucial is the dosage. In general, those who do not aspire to fame in the field of writing scandalous reviews are best advised to use moderate language. It would be a misconception to assume that criticism of the content of a book is best formulated in linguistically drastic terms. On the contrary, it is in the interest of reviewers not to scare off parts of the readership through drastic form and style but instead to ensure the best possible reception by preferring a neutral style that signals objectivity.

\section{FUNDING}

Open Access funding enabled and organized by Projekt DEAL.

\section{OPEN ACCESS}

This article is licensed under a Creative Commons Attribution 4.0 International License, which permits use, sharing, adaptation, dis-

${ }^{31}$ Schulze-Fielitz in Burgi, Zur Lage der Verwaltungsrechtswissenschaft, 179 (202).

${ }^{32}$ For instance, see the last sentence of a book review penned by Werner Heun (Die Verwaltung 45 [2020], 290 [293]), which (according to Schulze-Fielitz in Burgi, Zur Lage der Verwaltungsrechtswissenschaft, 179 (202 Fn. 97) elicited censure requests from the book's author. 
tribution and reproduction in any medium or format, as long as you give appropriate credit to the original author(s) and the source, provide a link to the Creative Commons licence, and indicate if changes were made. The images or other third party material in this article are included in the article's Creative Commons licence, unless indicated otherwise in a credit line to the material. If material is not included in the article's Creative Commons licence and your intended use is not permitted by statutory regulation or exceeds the permitted use, you will need to obtain permission directly from the copyright holder. To view a copy of this licence, visit http://creativecommons. org/licenses/by $/ 4.0 /$.

Publisher's Note Springer Nature remains neutral with regard to jurisdictional claims in published maps and institutional affiliations. 